\title{
Donor/acceptor nanoparticle pair-based singlet oxygen channeling homogenous chemiluminescence immunoassay for quantitative determination of bisphenol $A$
}

\author{
Changjiang Hou ${ }^{1,2} \cdot$ Lixia Zhao $^{1} \cdot$ Fanglan Geng $^{1} \cdot$ Dan Wang ${ }^{1} \cdot$ Liang-Hong Guo ${ }^{1,3}$
}

Received: 13 February 2016 /Revised: 6 April 2016 / Accepted: 19 April 2016 / Published online: 29 April 2016

(C) Springer-Verlag Berlin Heidelberg 2016

\begin{abstract}
Bisphenol A (BPA) is widely used in consumer products such as plastic bottles and food containers. It has become a ubiquitous environmental contaminant and poses a serious risk to human health. A rapid, sensitive, and highthroughput method for detecting BPA is therefore desirable. Herein, a donor/acceptor nanoparticle pair-based singlet oxygen channeling chemiluminescence homogenous immunoassay is developed for the determination of BPA. The donor nanoparticles were modified with phthalocyanine as a photosensitizer and were then coated with streptavidin. The acceptor nanoparticles were doped with thioxene derivatives and $\mathrm{Eu}(\mathrm{III})$ as a chemiluminescence emitter and then coated with anti-BPA antibody. Under light irradiation, oxygen near the donor surface transforms to singlet oxygen $\left({ }^{1} \mathrm{O}_{2}\right)$, which migrates to the acceptor and reacts with it, generating luminescence. Because ${ }^{1} \mathrm{O}_{2}$ has a very short lifetime, luminescence is generated only when the donor and acceptor are in close
\end{abstract}

Published in the topical collection Highlights of Analytical Chemical Luminescence with guest editors Aldo Roda, Hua Cui, and Chao Lu.

Electronic supplementary material The online version of this article (doi:10.1007/s00216-016-9584-y) contains supplementary material, which is available to authorized users.

Lixia Zhao

zlx@rcees.ac.cn

$\triangle$ Liang-Hong Guo

lhguo@rcees.ac.cn

1 State Key Laboratory of Environmental Chemistry and Ecotoxicology, Research Center for Eco-Environmental Sciences, Chinese Academy of Sciences, P.O. Box 2871, Beijing 100085, China

2 University of Chinese Academy of Sciences, Beijing 100049, China

3 Institute of Environment and Health, Jianghan University, Wuhan, Hubei 430056, China proximity. This occurs when they are brought together by the antigen/antibody and streptavidin/biotin reaction. Based on this singlet oxygen channeling mechanism, a competitive homogenous chemiluminescence immunoassay for BPA was developed on 384 microplates. The assay exhibited linear detection over the range $10-1000 \mathrm{ng} / \mathrm{mL}$ and a limit of detection of $2.9 \mathrm{ng} / \mathrm{mL}$. The intra- and inter-assay precisions were both below $5.1 \%$. The average recoveries of three spiked samples in tap and river water samples were in the range 95.5$121.0 \%$, in agreement with values obtained using highperformance liquid chromatography. The homogeneous assay is rapid, low cost, sensitive, and allows high-throughput, so is well suited for screening large numbers of environmental samples.

Keywords Homogenous immunoassay · Bisphenol A · Chemiluminescence $\cdot$ Oxygen channeling

\section{Introduction}

Bisphenol A [BPA; 2,2-bis(4-hydroxyphenyl)propane] has received increasing attention because of its widespread application and adverse effects on human health. It has recognized estrogenic-like properties $[1,2]$ and has been associated with breast carcinogenesis [3] and neurotoxic effects [4]. BPA also has negative effects on embryonic development [5], resulting in abortion, precocity, and preeclampsia [6,7]. BPA is an important basic organic raw material. It is widely used for producing polycarbonate plastics $[8,9]$, epoxy resins such as baby bottles, plastic containers for food and water, and lacquer coatings on food cans [10]. Even though BPA is hydrophobic, it still readily migrates into the environment in various ways. These include the high-temperature processing of BPA containers and contact with widely used liposoluble components 
[11]. The presence of BPA in aquatic environments has been reported [12]. Even low levels of BPA in aquatic ecosystems can adversely affect aquatic life [13]. It is therefore important to establish an effective and high-throughput method for detecting BPA in environmental samples.

BPA is frequently quantified by gas chromatography coupled with mass spectrometry (GC/MS) [14-18], highperformance liquid chromatography (HPLC) [19-21], and liquid chromatography coupled with mass spectrometry (LC/MS or LC/MS/MS) [16, 22-24]. These methods allow high sensitivity and specificity but are labor intensive, expensive, and time consuming because of their complex pretreatment steps. For example, due to the low volatility of BPA, it does need some derivatization step prior to chromatographic separation and GC/MS detection [18]. Although the derivatization step is not necessary in LC, some extraction steps, such as solidphase extraction (SPE) and liquid-liquid extraction (LLE), have been applied for the detection of BPA [16]. These techniques are also expensive and require skilled instrument operators so are unsuitable for analyzing large sample numbers.

In contrast, immunoassay methods are cost-effective and easy to use, so these have been widely applied to detect BPA. Enzyme-linked immunosorbent assay (ELISA) [25], fluorescence immunoassay (FI) [26], chemiluminescence enzymelinked immunosorbent assay (CL-ELISA) [27], and fluorescence polarization immunoassay (FPIA) [28] have been developed to detect BPA in environmental and food samples. ELISA, FI, and CL-ELISA are heterogeneous methods. They require immobilization of the solid phase, multiple washing steps to remove non-specifically absorbed material, and at least $3 \mathrm{~h}$ to achieve immunoreactions [29]. Thus, they are still time consuming, and their precision can vary. While homogeneous immunoassay requires no separation or washing steps, so it is only limited by the immunoreaction time. This makes homogeneous immunoassay practical for the rapid analysis of food and environmental samples. For example, a FPIA homogeneous immunoassay has been reported for the determination of BPA [28], but its sensitivity was limited, and its single tube design restricted rapid detection and highthroughput. There is much demand for a better homogenous immunoassay for the rapid, sensitive, and high-throughput analysis of BPA in environmental samples.

Chemiluminescence $(\mathrm{CL})$ has become very popular as an analytical technique in recent years, as they offer significant gains in sensitivity without interference from background light and rapidity at a low cost, both in instrumentation and materials [30-33]. While, to the best of our knowledge, there was no report about chemiluminescence homogenous immunoassay for the detection of BPA, in this study, we developed a singlet oxygen channeling chemiluminescence homogenous immunoassay for the quantitative determination of BPA in environmental water samples. The immunoassay is based on the formation of nanoparticle pairs and luminescence oxygen channeling immunoassay technology $[34,35]$. It involves a 384-well-based mix-and-read chemiluminescence assay without requiring washing steps and can analyze 384 samples within $130 \mathrm{~min}$. Due to the narrow wavelength scope and high quantum yields of emission, the chemiluminescence signal can be sensitively detected. After optimizing the donor-acceptor nanoparticles, biotin-BPA concentration, incubation time, and buffer solutions, the immunoassay was used to detect BPA in environmental samples. These results were validated by simultaneous HPLC detection. The results indicated that the method was rapid, sensitive, and effective for the highthroughput detection of BPA and was suitable for the largescale analysis of environmental samples.

\section{Materials and methods}

\section{Apparatus and reagents}

BPA, biotinylated BPA (biotin-BPA, $12.5 \mathrm{mg} / \mathrm{mL}$ ), and mouse anti-BPA monoclonal antibodies $(5.3 \mathrm{mg} / \mathrm{mL})$ were purchased from Wuxi JieshengJiekang Bio-Tech Co., Ltd. (Wuxi, People's Republic of China). Acceptor nanoparticles (5 mg/ $\mathrm{mL}, 200 \mathrm{~nm}$ ) coated with a second antibody (rabbit antimouse $\operatorname{IgG})$, donor nanoparticles $(5 \mathrm{mg} / \mathrm{mL}, 200 \mathrm{~nm})$ coated with streptavidin, and low cross-talk 384-well Optiplates were purchased from PerkinElmer (Waltham, MA, USA). Diphenolic acid (BVA), hydroquinone, phenol, and benzene were purchased from Sigma-Aldrich (St. Louis, MO, USA). Methanol, acetonitrile, HEPES, casein, Dextran-500, Triton X-100, and Proclin-300 were from PerkinElmer (Waltham, MA, USA). All chemicals, unless otherwise stated, were of analytical reagent grade and were used without further treatment. Water used in all procedures was Milli-Q grade.

$\mathrm{CL}$ measurements were performed at room temperature using an EnVision reader (PerkinElmer, USA) equipped with a $680-\mathrm{nm}$ excitation source and $570-\mathrm{nm}$ emission filter. The flash/time ratio was 0.55 , measurement height was $1 \mathrm{~mm}$, excitation time was $0.18 \mathrm{~s}$, and emission time was $0.37 \mathrm{~s}$. HPLC analysis was performed using an LC1260 instrument (Agilent, USA).

\section{Buffers and calibrators}

The assay buffer was $25 \mathrm{mM}$ HEPES, $\mathrm{pH} 7.4$, containing $0.1 \%$ casein $(w / v), 1 \mathrm{mg} / \mathrm{mL}$ Dextran-500, $0.5 \%$ Triton X$100(w / v)$, and $0.05 \%$ Proclin-300 $(w / v)$. The anti-BPA antibody and biotin-BPA antigen dilution buffer was $25 \mathrm{mM}$ assay buffer containing $0.9 \%(w / v) \mathrm{NaCl}, \mathrm{pH}$ 7.4.

A $0.1-\mathrm{mg} / \mathrm{mL}$ BPA stock solution was prepared in $10 \%$ methanol solution and stored at $-20{ }^{\circ} \mathrm{C}$. For calibration, dilutions of the stored solution were prepared in assay buffer for 0 , $10,30,100,300$, and $1000 \mathrm{ng} / \mathrm{mL}$ concentrations, designated 
as $\mathrm{S}_{0}, \mathrm{~S}_{1}, \mathrm{~S}_{2}, \mathrm{~S}_{3}, \mathrm{~S}_{4}, \mathrm{~S}_{5}$, and $\mathrm{S}_{6}$, respectively. These solutions were stored at $4{ }^{\circ} \mathrm{C}$.

\section{Immunoassay procedure}

The mixture of $5 \mu \mathrm{L}$ of biotin-BPA and $5 \mu \mathrm{L}$ of BPA standard or water sample was added into the wells of the 384-microtiter well plate. Ten microliters of mouse anti-BPA antibody and $10 \mu \mathrm{L}$ of acceptor nanoparticles coated with a second antibody were then added. The plates were agitated, sealed, and allowed to stand at room temperature $\left(23 \pm 0.5{ }^{\circ} \mathrm{C}\right)$ for $100 \mathrm{~min}$. This ensured sufficient mixing and completion of the competitive reaction of biotin-BPA and BPA standard with mouse anti-BPA antibodies, which can also be captured by the second antibody-bound acceptor nanoparticles. Twenty microliters of streptavidin-coated donor nanoparticles were then added, and the mixture was incubated at room temperature (in the dark) for another $30 \mathrm{~min}$. Through the specific interaction of biotin-streptavidin, nanoparticle pairs were formed with nanoparticles within $200 \mathrm{~nm}$ of each other. The CL signal was measured with an EnVision reader, with an excitation wavelength of $680 \mathrm{~nm}$ and detection wavelength of $618 \mathrm{~nm}$.

\section{Data treatment}

Standards and samples were run in double wells, and mean $\mathrm{CL}$ intensity values were processed. Standard curves and paired $t$ test were obtained by plotting CL intensity against the logarithm of analyte concentration, using GraphPad Prism software. The reproducibility was evaluated by analyzing six wells within a plate, using three different concentration samples. These samples were also analyzed on three different days using the same protocol, to determine the inter-assay precision.

\section{Cross-reactivity assessment and method validation using HPLC}

Some structural analogs of BPA were studied for cross-reactivity, to assess the specificity of the antibody and the proposed method. HPLC equipped with a C18 column was used to analyze the BPA concentrations, using the following detection conditions: mobile phase was $0.01 \mathrm{~mol} / \mathrm{L}$ mixture of ammonium acetate solution and acetonitrile $(V / V, 55: 45)$, mobile phase flow rate was $0.3 \mathrm{~mL} / \mathrm{min}$, column temperature was $30{ }^{\circ} \mathrm{C}$, and detection wavelength was $278 \mathrm{~nm}$.

\section{Real water samples}

River and tap water samples were collected from the Qinghe River (Beijing, People's Republic of China) and our laboratory, respectively. The samples were centrifuged and filtered through a $0.22-\mu \mathrm{m} \mathrm{GF/C}$ glass microfiltration membrane.

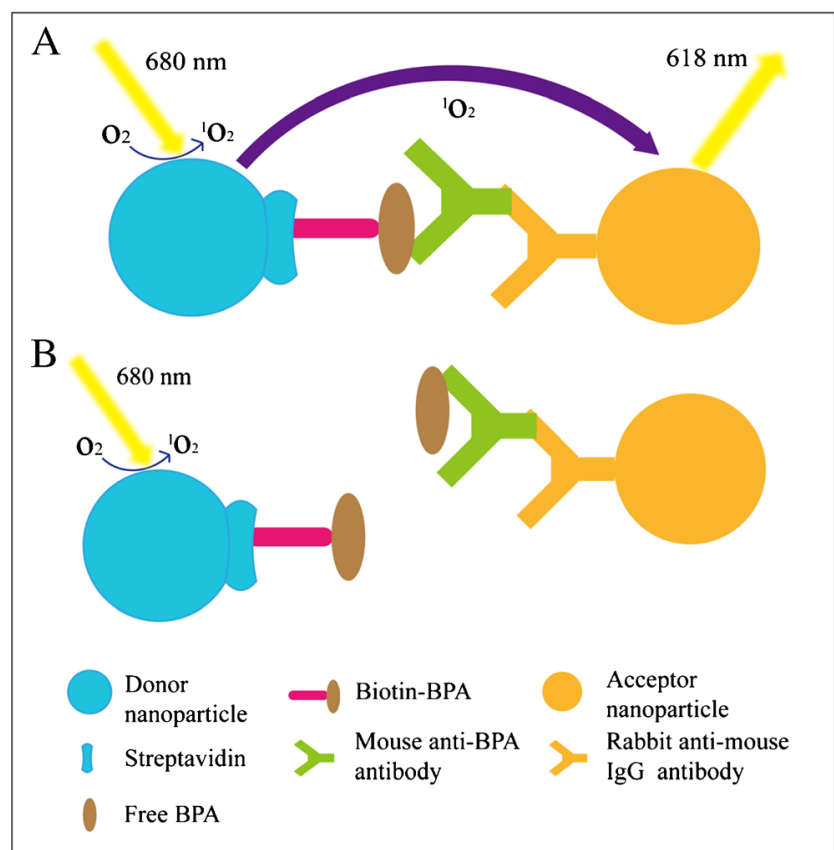

Fig. 1 Principle of the singlet oxygen channeling homogenous chemiluminescence immunoassay based on nanoparticle pairs. (A) The "before adding BPA" stage. (B) The "after adding BPA" stage

BPA was then injected into these water samples in different concentrations. These samples were analyzed using the immunoassay, and the results were compared with those from HPLC detection.

\section{Results and discussion}

According to the principles of singlet oxygen channeling homogeneous chemiluminescence immunoassay, various assay component concentrations (nanoparticles, immunoreaction reagents) and reaction conditions were studied to (1) optimize the immunoassay sensitivity and (2) study immunoassay performance under optimum conditions. Experiments were carried out using the method described above. Varying CL intensities and BPA concentrations causing $50 \%$ inhibition $\left(\mathrm{IC}_{50}\right)$ of the standard curves were evaluated under different conditions.

\section{Singlet oxygen channeling homogenous chemiluminescence immunoassay for BPA measurement}

The principles of the proposed immunoassay are shown in Fig. 1. It involves two types of polystyrene nanoparticles: donor nanoparticles modified with phthalocyanine as a photosensitizer and acceptor nanoparticles coated with thioxene derivatives and $\mathrm{Eu}(\mathrm{III})$ dopant as a chemiluminescer. These nanoparticles were both coated with a hydrogel that provides 
A

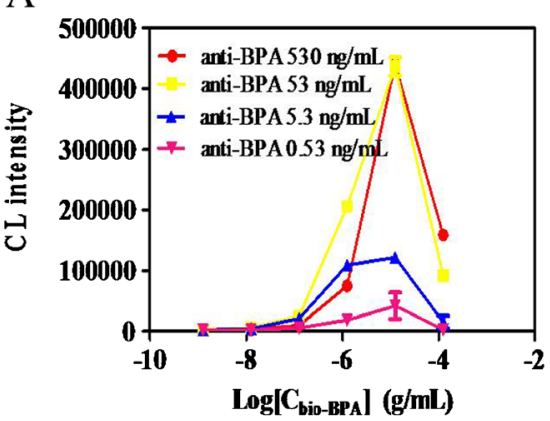

$\mathrm{C}$

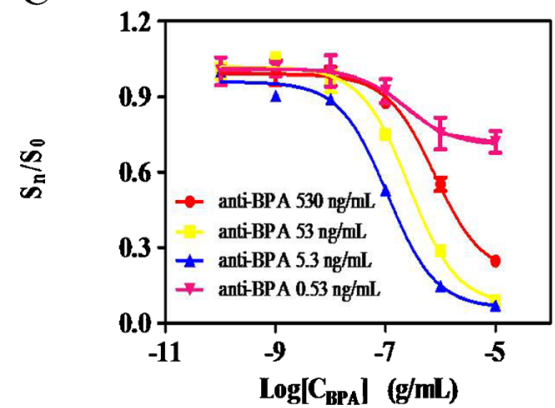

Fig. 2 (A) Titration curves of biotin-BPA and anti-BPA antibody prepared in assay buffer. Biotin-BPA concentrations $(1.25,12.5,125$, and $1250 \mathrm{ng} / \mathrm{mL}, 12.5$, and $125 \mu \mathrm{g} / \mathrm{mL}$ ) and anti-BPA antibody concentrations $(530,53,5.3$, and $0.53 \mathrm{ng} / \mathrm{mL})$ were examined. (B) Competitive curves generated using $1250 \mathrm{ng} / \mathrm{mL}$ biotin-BPA and different concentrations of anti-BPA antibody. Competitive curves were

reactive aldehyde groups for conjugating biomolecules to the bead surface. Under irradiation at $680 \mathrm{~nm}, \mathrm{O}_{2}$ near the surface of the photosensitizer transforms to singlet oxygen $\left({ }^{1} \mathrm{O}_{2}\right)$ which has been proven by [34]. ${ }^{1} \mathrm{O}_{2}$ has a short life span of
B

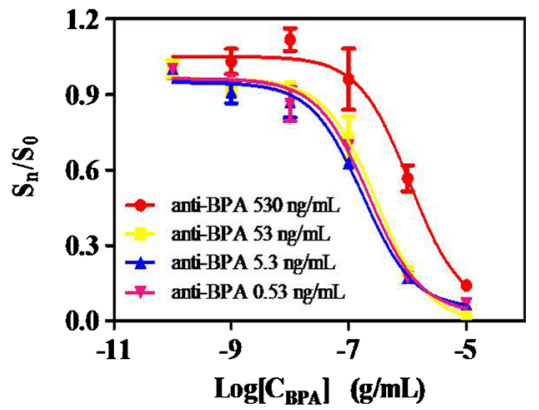

D

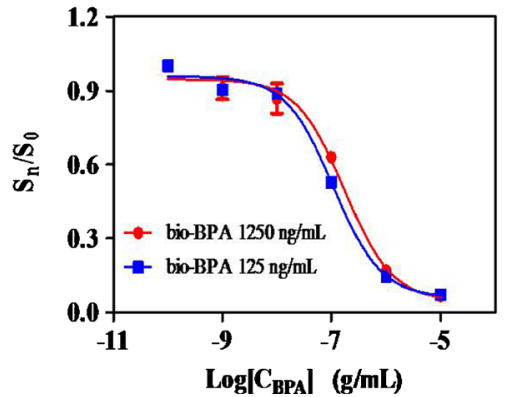

prepared with double-well replicates. (C) Competitive curves generated using $125 \mathrm{ng} / \mathrm{mL}$ biotin-BPA and different concentrations of anti-BPA antibody. (D) Competitive curves generated using $5.3 \mathrm{ng} / \mathrm{mL}$ anti-BPA antibody and 125 or $1250 \mathrm{ng} / \mathrm{mL}$ biotin-BPA, $150 \mu \mathrm{g} / \mathrm{mL}$ donor nanoparticles, and $200 \mu \mathrm{g} / \mathrm{mL}$ acceptor nanoparticles. Incubation times for the two-step assay were 120 and $30 \mathrm{~min}$, respectively

$4 \mu \mathrm{s}$, resulting in an effective migration distance of $200 \mathrm{~nm}$ $[34,35]$. The two nanoparticles approach each other through the specific reaction of the antigen-antibody and biotinstreptavidin. The resulting donor-acceptor nanoparticle pairs
Fig. 3 Effect of (A) donor and

(B) acceptor nanoparticles on the

CL intensity for the singlet

oxygen channeling

chemiluminescence

homogeneous immunoassay of

BPA. (C) Effect of incubation

time on the competition

immunoassay of BPA. The

analyte, biotin-BPA, and anti-

BPA antibody and acceptor nanoparticles were incubated for 50-120 min. The results were extracted from the semi-log equation used to fit the standard curves. Standard curves were prepared using double-well replicates
A

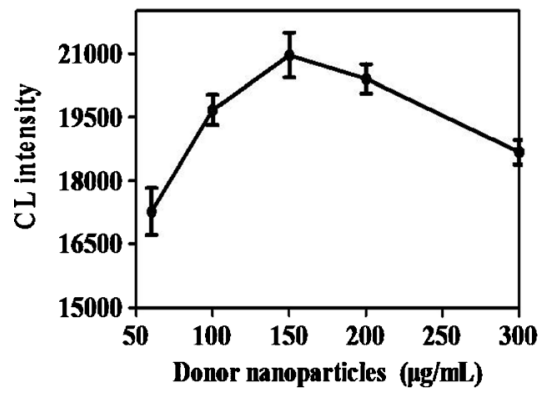

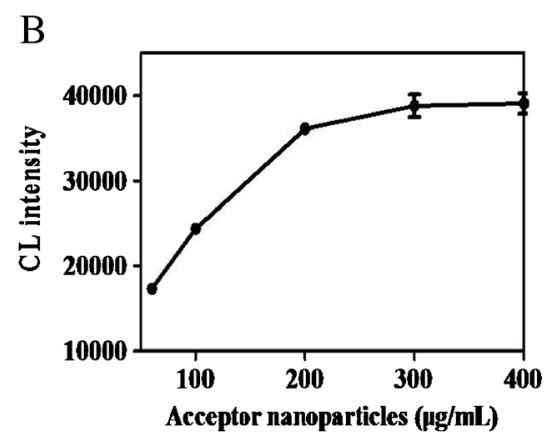

C

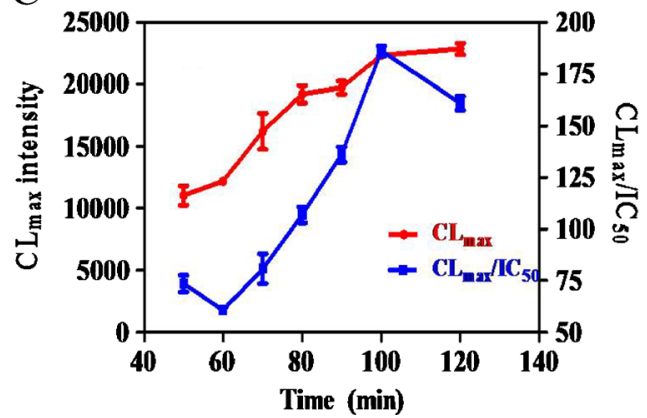




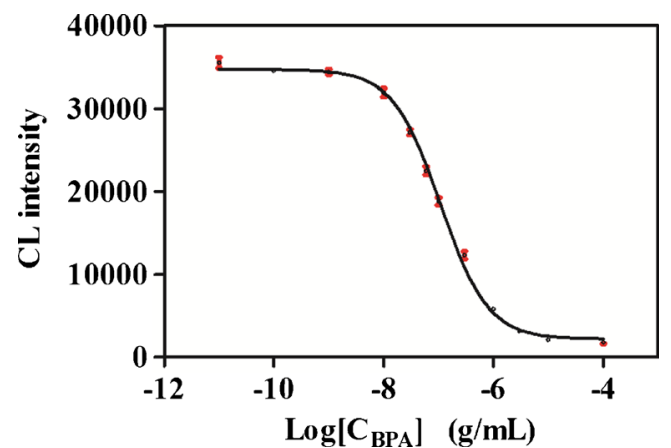

Fig. 4 Calibration curve of the singlet oxygen channeling homogenous chemiluminescence immunoassay for detecting BPA in environmental water samples

contain the two nanoparticle types within $200 \mathrm{~nm}$ of each other $[36,37] .{ }^{1} \mathrm{O}_{2}$ then transfers to the acceptor beads and reacts with the $\mathrm{CL}$ emitter, generating emission at $618 \mathrm{~nm}$.

\section{Titration assessment of anti-BPA antibody and biotin-BPA}

The concentrations of anti-BPA antibody and biotin-BPA are important parameters for the immunoassay sensitivity. BiotinBPA was progressively diluted from $125 \mu \mathrm{g} / \mathrm{mL}$ to $1.25 \mathrm{ng} /$ $\mathrm{mL}$, and anti-BPA antibody was diluted to 530, 53, 5.3, and $0.53 \mathrm{ng} / \mathrm{mL}$ in assay buffers. These dilutions were used to obtain the titration curves shown in Fig. 2a. Similarly to reported competitive immunoassays [37], the "hook" effect was observed with increasing biotin-BPA concentration. When the concentration of biotin-BPA was $12.5 \mu \mathrm{g} / \mathrm{mL}$, the CL signal reached a maximum at a different concentration of anti-BPA antibody. This indicated that the nanoparticle binding capacity became saturated at the hook point. The $1250-$ and $125-\mathrm{ng} / \mathrm{mL}$ biotin-BPA concentrations occurring near the sub-hook concentration were used for subsequent experiments.

In general, less antibody results in higher sensitivity for a competitive reaction. In total, $0.53,5.3,53$, and $530 \mathrm{ng} / \mathrm{mL}$
anti-BPA antibody concentrations were determined, using the standard curves in the concentration range $10-1000 \mathrm{ng} / \mathrm{mL}$. The results (Fig. 2b, c) showed that for 1250 or $125 \mathrm{ng} / \mathrm{mL}$ biotin-BPA concentration, the highest sensitivity was obtained at an anti-BPA antibody titration concentration of $5.3 \mathrm{ng} / \mathrm{mL}$. This was probably due to excess capture antibody, resulting in superposition and denaturalization of the intra-protein. Insufficient capture antibody would be expected to adversely affect CL intensity and sensitivity. The $1250-$ and $125-\mathrm{ng} / \mathrm{mL}$ biotin-BPA conjugate concentrations were evaluated using $5.3 \mathrm{ng} / \mathrm{mL}$ anti-BPA antibody. The resulting competition curves were as shown in Fig. 2d. The assay using $125 \mathrm{ng} /$ $\mathrm{mL}$ biotinylated tracer provided higher sensitivity than that with a concentration of $1250 \mathrm{ng} / \mathrm{mL}$. Therefore, titration levels of $5.3 \mathrm{ng} / \mathrm{mL}$ for anti-BPA antibody and $125 \mathrm{ng} / \mathrm{mL}$ for biotinBPA were used in subsequent experiments.

\section{Optimization of donor and acceptor nanoparticles}

The properties of the donor and acceptor nanoparticles mainly affect the sensitivity and linear range of the immunoassay, and they have nothing to do with other properties such as crossreactivity which are related to the specificity of the used antibody. Excess of either nanoparticle type increases the background signal, which decreases the linear range. Too little of either decreases the CL signal, which decreases the assay sensitivity. The concentrations of donor and acceptor nanoparticles must be optimized to obtain the best CL signal and to avoid wasting materials. Five different concentrations of donor nanoparticles coated with streptavidin $(60,100,150,200$, and $300 \mu \mathrm{g} / \mathrm{mL}$ ) were investigated. The results (Fig. 3a) showed that CL intensity increased with increasing donor nanoparticle concentration in the range $60-150 \mu \mathrm{g} / \mathrm{mL}$. Concentrations higher than $150 \mu \mathrm{g} / \mathrm{mL}$ resulted in a slow decrease in CL intensity with increasing donor nanoparticle concentration. This was probably because the phthalocyanine modified the surface of donor nanoparticles had a weak

Table 1 Comparison of the analytical performance of proposed method with others

\begin{tabular}{llllll}
\hline Method & Type & LOD $(\mathrm{ng} / \mathrm{mL})$ & Linear range or $\mathrm{IC}_{50}(\mathrm{ng} / \mathrm{mL})$ & Analysis times/each sample (min) & Reference \\
\hline FI-CL & Non-immune & 70.68 & $182.4 \sim 2736$ & - & - \\
$\mathrm{CL}^{-A u C l}{ }_{4}^{-}-\mathrm{HCO}_{4}{ }^{-}$ & Non-immune & 18.24 & $68.4 \sim 18,240$ & 3.75 & {$[39]$} \\
CLEIA & Heterogeneous & 8.0 & $10 \sim 740$ & 3.125 & 10.2 \\
Cd-doped-ZnO QDs FLISA & Heterogeneous & 13.1 & $20.8 \sim 330.3$ & - & {$[40]$} \\
FPIA & Homogeneous & 5.6 & $11.32 \sim 904.21$ & 0.625 \\
CL-luminol-KMnO & Non-immune & 0.0228 & $0.228-2280$ & 0.338 \\
CL-ELISA & Heterogeneous & 0.02 & 0.2 & {$[42]$} \\
The proposed method & Homogeneous & 2.9 & $10 \sim 1000$ & {$[43]$} \\
\hline
\end{tabular}

FI-CL flow injection chemiluminescence method, CLEIA chemiluminescence enzyme immunoassay, Cd-doped-ZnO QDs FLISA Cd-doped ZnO quantum dot-based fluorescence-linked immunoassay, FPIA fluorescence polarization immunoassay, CL-ELISA chemiluminescence enzyme-linked immunosorbent assay 
Table 2 Intra- and inter-assay precision for detecting BPA using the proposed immunoassay

\begin{tabular}{|c|c|c|c|c|c|}
\hline & Number & Mean (ng/mL) & Range (ng/mL) & SD & C.V. $(\%)$ \\
\hline \multirow[t]{3}{*}{ Intra-assay $(n=6)$} & 1 & 47.3 & $46.0-50.5$ & 2.2 & 4.6 \\
\hline & 2 & 102.7 & $95.6-108.1$ & 5.3 & 5.1 \\
\hline & 3 & 508.3 & $491.4-525.0$ & 13.9 & 2.7 \\
\hline \multirow[t]{3}{*}{ Inter-assay ( $n=12$, detection of 3 days) } & 1 & 49.4 & $46.0-52.4$ & 1.0 & 2.0 \\
\hline & 2 & 104.5 & $95.4-114.4$ & 3.0 & 2.9 \\
\hline & 3 & 506.4 & $477.4-523.9$ & 9.0 & 1.8 \\
\hline
\end{tabular}

absorption at $618 \mathrm{~nm}$ of which CL emission generated. When the donor nanoparticles were insufficient, the emitted light absorbed by donor was far below than that of generating due to the formation of nanoparticle pairs. Thus, the CL intensity increased with the increasing of donor nanoparticles. While, the concentrations greater than $150 \mathrm{ng} / \mathrm{mL}$, the formation of nanoparticle pairs reached the equilibrium status and the redundant donor nanoparticles would absorb the emitted light which leads to the CL signal a lower trend, for the acceptor nanoparticles shown in Fig. 3b, the CL signal intensity increased with increasing nanoparticle concentration in the range $60-200 \mu \mathrm{g} / \mathrm{mL}$. The $\mathrm{CL}$ signal intensity reached a plateau at $200 \mu \mathrm{g} / \mathrm{mL}$. Thus, when the acceptor concentration was $200 \mu \mathrm{g} / \mathrm{mL}$, the formation of nanoparticle pairs was in equilibrium. One hundred and fifty and $200 \mu \mathrm{g} / \mathrm{mL}$ concentrations of donor and acceptor nanoparticles were used in subsequent experiments, respectively.

\section{Optimization of incubation time}

The time available for immunoreagents to interact in a competitive ELISA reportedly affects the assay sensitivity [38]. Thus, we varied the length of the competitive step from 50 to $120 \mathrm{~min}$, to assess the effect of incubation time on assay performance $\left(\mathrm{IC}_{50}, \mathrm{CL}_{\max }\right.$ intensity, and $\left.\mathrm{CL}_{\max } / \mathrm{IC}_{50}\right)$. As shown in Fig. 3c, the CL intensity increased with longer incubation time in the range 50-100 $\mathrm{min}$. After $100 \mathrm{~min}$, the CL showed little further change, indicating the immunoassay between the antibody and antigen had reached equilibrium. Under these conditions, a very small difference was observed in the $\mathrm{IC}_{50}$ values. The variation in $\mathrm{CL}_{\max } / \mathrm{IC}_{50}$ ratio as a function of incubation time showed that a higher $\mathrm{CL}_{\max } / \mathrm{IC}_{50}$ was obtained after $100 \mathrm{~min}$, so all subsequent experiments were carried out using this incubation time. The reaction time between the streptavidin-coated donor nanoparticles and biotin-BPA was set as $30 \mathrm{~min}$, according to previous reports [36, 37].

\section{Optimization of buffer solutions}

To develop a highly effective homogeneous chemiluminescence immunoassay method for the detection of BPA, buffer components and $\mathrm{pH}$ should be investigated. In this study,
HEPES buffers including Dextran-500, Casein, Triton X100, and Proclin-300 were used. In which HEPES can provide stable surroundings for antibody-antigen-specific interaction, the presence of Dextran-500 was in order to prevent nonspecific bead aggregation, the Casein as a kind of protein blocker would reduce the antibody-nonspecific reaction, the surfactant Triton X-100 can enhance the solubility of immunoreagent and reduce the nonspecific adsorption, and the Proclin-300 as a kind of antiseptic can maintain the activity of antibody. Their effect of concentration of different components on assay performance $\left(\mathrm{IC}_{50}, \mathrm{CL}\right.$ intensity, and $\mathrm{CL}_{\text {max }} / \mathrm{IC}_{50}$ ) was systematically studied and the results were shown in Fig S1-S5 (see Electronic Supplementary Material, ESM). According the variation of $\mathrm{CL}$ intensity and $\mathrm{CL}_{\max } / \mathrm{IC}_{50}$, considering the less reagents comprehensively, all subsequent experiments were carried out using $25 \mathrm{mM}$ HEPES, $0.1 \%$ Casein $(w / v), 1 \mathrm{mg} /$ $\mathrm{mL}$ Dextran-500, $0.5 \%$ Triton X-100 (w/v), and $0.05 \%$ Proclin-300 $(w / v)$.

In additional, antigen-antibody binding was characterized by the weak intermolecular bonds, and $\mathrm{pH}$ value can affect the interaction. Figure S6 (see ESM) showed the effects of $\mathrm{pH}$ on the assay performance $\left(\mathrm{IC}_{50}, \mathrm{CL}_{\max }\right.$, and $\left.\mathrm{CL}_{\max } / \mathrm{IC}_{50}\right)$ in the proposed methods for BPA. Both $\mathrm{CL}$ intensity and $\mathrm{CL}_{\max } /$ $\mathrm{IC}_{50}$ reached the maximum in the $\mathrm{pH}$ 7.4. This behavior can be explained according to the isoelectric points $(\mathrm{pI})$ of the antibody. In this experiment, $\mathrm{pH} 7.4$ was chosen as the optimum condition.

\section{Assay sensitivity and linear range}

Under optimum conditions, dose-response curves were obtained with $5 \mu \mathrm{L}$ of BPA standard, and the CL of nanoparticles

Table 3 Reliability of singlet oxygen channeling homogenous chemiluminescence immunoassay for BPA detection

\begin{tabular}{lllll}
\hline & \multicolumn{4}{l}{ Dilution ratio } \\
\cline { 2 - 5 } & Neat & $1: 2$ & $1: 4$ & $1: 8$ \\
\hline Expected concentration $(\mathrm{ng} / \mathrm{mL})$ & 800.0 & 400.0 & 200.0 & 100.0 \\
Observed concentration $(\mathrm{ng} / \mathrm{mL})$ & 800.0 & 411.1 & 198.2 & 111.7 \\
Recovery (\%) & 100.0 & 102.8 & 99.1 & 111.7 \\
\hline
\end{tabular}


Table 4 Cross-reactivity with compounds related to BPA

\begin{tabular}{cc}
\hline Compound & Cross-reactivity (\%) \\
\hline Bisphenol A & $<0.01$ \\
Besorcinol & $<0.01$ \\
\hline Bhenol & $<0.01$ \\
\hline
\end{tabular}

pairs was detected, as shown in Fig. 4. The linear range was $10-1000 \mathrm{ng} / \mathrm{mL}$, with an equation of $Y=-13,450 \log x-75$, 000 and correlation coefficient of $r=0.9896$. The limit of detection (LOD), defined as the minimum dose distinguishable from 0 or the minimum detected concentration (mean-3SD of zero standard, eight replicates), of BPA was $2.9 \mathrm{ng} / \mathrm{mL}$. Compared with the reported CL analytical methods or FL homogenous immunoassay (Table 1), the proposed method showed the relatively higher sensitivity than the others except the report of [27, 43]. Moreover, it also showed the highest rapidity and can achieve the high-throughput screening detection.

\section{Assay precision (intra- and inter-assay variation)}

The assay precision was evaluated using spiked doubledistilled water with different concentrations of BPA in the detection range, as shown in Table 2. To determine the intraassay variation, three spiked samples were assayed in six replicates. The coefficients of variation $(\mathrm{CV})$ varied from 2.7 to $5.1 \%$, indicating very good intra-assay reproducibility. The inter-assay precision was determined from three independent experiments performed on different days. CV values below $10 \%$ were obtained for samples, which indicated very good inter-assay reproducibility.

\section{Assay accuracy}

Recovery was used to evaluate the reliability of the BPA detection method. One- to eightfold dilutions of spiked BPA water samples with an expected concentration of $800 \mathrm{ng} / \mathrm{mL}$ were prepared using the assay buffer. The respective concentrations were detected using the immunoassay, and the results are shown in Table 3. All recoveries were within the range $99.05-111.7 \%$.

\section{Cross-reactivity}

The specificity of the immunoreaction is an important factor in an immunological analysis. The specificity of the immunoassay depends on the antibody's specificity, but the immunoassay format can affect the specificity of the reaction. The crossreactivity of BPA was evaluated using analogs of bisphenol A with similar structures. These included diphenolic acid, hydroquinone, phenol benzene, and 4,4-bis(4-hydroxyphenol)

Table 5 Recoveries of BPA from spiked environmental water samples

\begin{tabular}{cllll}
\hline Sample & $\begin{array}{l}\text { Spiked } \\
\text { amount } \\
(\mathrm{ng} / \mathrm{mL})\end{array}$ & $\begin{array}{l}\text { Determined } \\
\text { amount } \\
(\mathrm{ng} / \mathrm{mL}, n=3)\end{array}$ & $\begin{array}{l}\text { Recovery } \\
(\%)\end{array}$ & $\begin{array}{l}\text { CV } \\
(\%)\end{array}$ \\
\hline Tap water & 0 & None & 101.9 & 15.5 \\
& 50 & 50.9 & 108.5 & 7.2 \\
& 100 & 108.5 & 101.5 & 12.5 \\
& 200 & 203.0 & 118.5 & 1.8 \\
& 400 & 474.1 & 113.0 & 6.3 \\
River & 600 & 678.1 & 99.0 & 11.2 \\
water & 0 & 990.4 & & \\
& 50 & None & 121.0 & 2.3 \\
& 1000 & 60.5 & 108.5 & 11.6 \\
& 200 & 108.5 & 112.0 & 7.6 \\
& 400 & 478.1 & 119.5 & 7.7 \\
& 600 & 717.2 & 119.5 & 1.8 \\
& 1000 & 954.7 & 95.5 & 4.7 \\
\hline
\end{tabular}




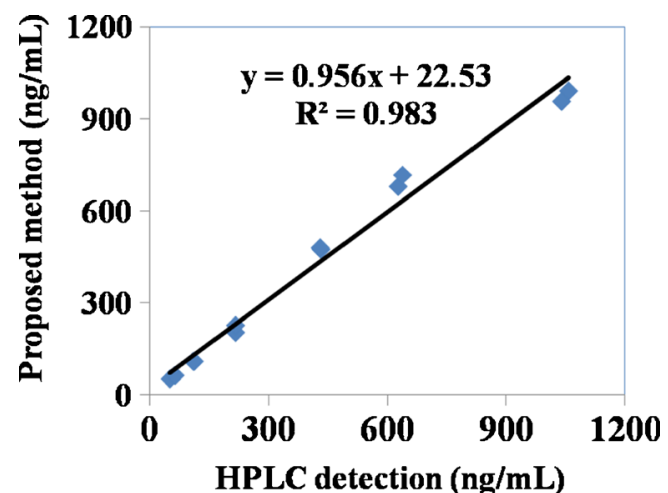

Fig. 5 Correlation plots for environmental water samples using the CL immunoassay and HPLC

valeric acid (BVA). The BPA concentration causing $50 \%$ inhibition was used to calculate the cross-reactivity (\%), according to the equation:

Cross-reactivity $(\%)=\frac{\mathrm{IC}_{\mathrm{so}} \mathrm{BPA}}{\mathrm{IC}_{\mathrm{so}} \mathrm{BPA} \text { analogs }} \times 100 \%$

Table 4 showed the cross-reactivity of the anti-BPA antibody. The antibody exhibited $122.6 \%$ cross-reactivity with BVA. This was due to BVA and BPA both having structures with double phenolic rings connected via a carbon atom, which acts as an antigenic determinant [42]. Crossreactivities with other related compounds were all less than $1 \%$. Therefore, the anti-BPA antibody was generally specific to BPA, and other structurally related compounds were not recognized.

\section{Analysis of environmental water samples}

The applicability of the assay for ecological monitoring was investigated in experiments with environmental samples, and the results were compared with those from HPLC detection. Some articles report difficulties in analyzing complex environmental matrices by ELISA. Oubina et al. reported that adding a buffer solution to samples reduced the matrix effects

Table 6 The paired $t$ test of HPLC and immunoassay at all standard addition concentration in tap and river water

\begin{tabular}{llllll}
\hline & \multicolumn{3}{l}{ Tap water } & & \multicolumn{2}{l}{ River water } \\
\cline { 2 - 3 } \cline { 5 - 6 } Concentration $(\mathrm{ng} / \mathrm{mL})$ & $t(d f=4)$ & $P$ value & & $t(d f=4)$ & $P$ value \\
\hline 50 & 0.32 & 0.77 & & 0.87 & 0.43 \\
100 & 0.69 & 0.52 & & 0.54 & 0.62 \\
200 & 0.37 & 0.73 & 0.20 & 0.85 \\
400 & 0.85 & 0.44 & 1.12 & 0.33 \\
600 & 1.96 & 0.12 & 1.75 & 0.16 \\
1000 & 0.63 & 0.56 & & 1.63 & 0.18 \\
\hline
\end{tabular}

[44]. Therefore, tap and river water samples were buffered using the assay buffer for the CL immunoassay.

Tap and river water were collected from water sources in our laboratory and the Qinghe River, respectively. Samples were spiked with BPA and analyzed using the singlet oxygen channeling homogenous chemiluminescence immunoassay. Recoveries of water samples spiked at 0, 50, 100, 200, 400, 600 , and $1000 \mathrm{ng} / \mathrm{mL}$ were examined in triplicate, using distilled water as a control. The recoveries of spiked water and river water are shown in Table 5. They were in the range 95.5$121.0 \%$, indicating that the method can determine BPA in environmental water samples.

The spiked BPA concentrations in the samples were simultaneously determined by HPLC. Results from the two methods correlated well, as shown in Fig. 5. And the paired $t$ test $P$ value of two methods at all standard addition concentrations in tap and river water were shown in Table 6 and Figs. S7-S8 (see ESM). From the results, we can see all the $P$ values were greater than 0.05 , which indicated the detection results of both methods have no obvious difference.

\section{Conclusions}

A high-throughput CL homogeneous immunoassay was developed and optimized for quantitatively determining BPA in water samples. The assay is based on the formation of nanoparticle pairs and the transfer of singlet oxygen. This two-step assay has high precision and a broad dynamic range, is simple, rapid, and reliable, allows high-throughput, and has low reagent consumption. The assay can also be easily automated. It allows the routine analysis of BPA in water samples without complex pretreatment and can potentially be applied in other matrices such as biological fluids and plastics.

Acknowledgments The authors gratefully acknowledge financial support of the Chinese Academy of Sciences (XDB14040100), National Basic Research Program of China (973 program, 2015CB932003), and National Natural Science Foundation of China (Nos. 21177138, 21321004, 21527901, 91543203).

Compliance with ethical standards

Conflict of interest The authors declare no conflicts of interest.

\section{References}

1. Grignard E, Lapenna S, Bremer S. Weak estrogenic transcriptional activities of Bisphenol A and Bisphenol S. Toxicol in Vitro. 2012;26:727-31.

2. Takagi H, Shibutani M, Masutomi N, Uneyama C, Takahashi N, Mitsumori K, et al. Lack of maternal dietary exposure effects of 
bisphenol A and nonylphenol during the critical period for brain sexual differentiation on the reproductive/endocrine systems in later life. Arch Toxicol. 2004;78:97-105.

3. Zhang XL, Wang HS, Liu N, Ge LC. Bisphenol A stimulates the epithelial mesenchymal transition of estrogen negative breast cancer cells via FOXA1 signals. Arch Biochem Biophys. 2015;585: $10-6$.

4. Le HH, Carlson EM, Chua JP, Belcher SM. Bisphenol A is released from polycarbonate drinking bottles and mimics the neurotoxic actions of estrogen in developing cerebellar neurons. Toxicol Lett. 2008;176:149-56.

5. Yin N, Yao X, Qin Z, Wang YL, Faiola F. Assessment of Bisphenol A (BPA) neurotoxicity in vitro with mouse embryonic stem cells. J Environ Sci. 2015;36:181-7.

6. Lathi RB, Liebert CA, Brookfield KF, Taylor JA, vom Saal FS, Fujimoto VY, et al. Conjugated bisphenol A in maternal serum in relation to miscarriage risk. Fertil Steril. 2014;102:123-8.

7. Fernandez M, Bianchi M, Lux-Lantos V, Libertun C. Neonatal exposure to bisphenol A alters reproductive parameters and gonadotropin releasing hormone signaling in female rats. Environ Health Perspect. 2009; 117:757-62.

8. Vidal RB, Ibanez GA, Escandar GM. Chemometrics-assisted cyclodextrin-enhanced excitation-emission fluorescence spectroscopy for the simultaneous green determination of bisphenol $\mathrm{A}$ and nonylphenol in plastics. Talanta. 2015;143:162-8.

9. Song H, Zhang T, Yang P, Li M, Yang Y, Wang Y, et al. Low doses of bisphenol A stimulate the proliferation of breast cancer cells via ERK1/2/ERRgamma signals. Toxicol in Vitro. 2015;30:521-8.

10. Rajasarkka J, Koponen J, Airaksinen R, Kiviranta H, Virta M. Monitoring bisphenol A and estrogenic chemicals in thermal paper with yeast-based bioreporter assay. Anal Bioanal Chem. 2014;406: 5695-702.

11. Ji W, Du L, Zhang Y, Liu G, Wang S. Ultrasensitive fluorescence immunoassay for detection of bisphenol A in milk products using functionalized gold nanoparticles as probe. Food Anal Methods. 2015;8:2596-604.

12. Song S, Ruan T, Wang T, Liu R, Jiang G. Distribution and preliminary exposure assessment of bisphenol AF (BPAF) in various environmental matrices around a manufacturing plant in China. Environ Sci Technol. 2012;46:13136-43.

13. Yamaguchi A, Ishibashi $\mathrm{H}$, Arizono $\mathrm{K}$, Tominaga $\mathrm{N}$. In vivo and in silico analyses of estrogenic potential of bisphenol analogs in medaka (Oryzias latipes) and common carp (Cyprinus carpio). Ecotoxicol Environ Saf. 2015;120:198-205.

14. Deceuninck Y, Bichon E, Durand S, Bemrah N, Zendong Z, Morvan ML, et al. Development and validation of a specific and sensitive gas chromatography tandem mass spectrometry method for the determination of bisphenol A residues in a large set of food items. J Chromatogr A. 2014;1362:241-9.

15. Johnson BO, Burke FM, Harrison R, Burdette S. Quantitative analysis of Bisphenol A leached from household plastics by solid-phase microextraction and gas chromatography-mass spectrometry (SPME-GC-MS). J Chem Educ. 2012;89:1555-60.

16. Ros O, Vallejo A, Blanco-Zubiaguirre L, Olivares M, Delgado A, Etxebarria N, et al. Microextraction with polyethersulfone for bisphenol-A, alkylphenols and hormones determination in water samples by means of gas chromatography-mass spectrometry and liquid chromatography-tandem mass spectrometry analysis. Talanta. 2015;134:247-55.

17. Deceuninck Y, Bichon E, Marchand P, Boquien CY, Legrand A, Boscher C, et al. Determination of bisphenol A and related substitutes/analogues in human breast milk using gas chromatography-tandem mass spectrometry. Anal Bioanal Chem. 2015;407:2485-97.

18. Azzouz A, Rascon AJ, Ballesteros E. Simultaneous determination of parabens, alkylphenols, phenylphenols, bisphenol A and triclosan in human urine, blood and breast milk by continuous solid-phase extraction and gas chromatography-mass spectrometry. J Pharm Biomed. 2016;119:16-26.

19. Qi L, Wang Y, Li Y, Zheng G, Li C, Su H. Microfluidic aqueous two-phase extraction of bisphenol A using ionic liquid for highperformance liquid chromatography analysis. Anal Bioanal Chem. 2015;407:3617-25.

20. Benhamada M, Bouzid D, Boyron O, Taam M. The relationship between the aging of polycarbonate characterized by SEC and the release of bisphenol A quantified by HPLC-UV. Eur Food Res Technol. 2015;242:227-32.

21. Gao L, Zou J, Liu H, Zeng J, Wang Y, Chen X. Determination of bisphenol $\mathrm{A}$ in thermal printing papers treated by alkaline aqueous solution using the combination of single-drop microextraction and HPLC. J Sep Sci. 2013;36:1298-303.

22. Vitku J, Chlupacova T, Sosvorova L, Hampl R, Hill M, Heracek J, et al. Development and validation of LC-MS/MS method for quantification of bisphenol A and estrogens in human plasma and seminal fluid. Talanta. 2015;140:62-7.

23. Trdan LT, Roskar R, Mrhar A. Evaluation of bisphenol A glucuronidation according to UGT1A $1 * 28$ polymorphism by a new LC-MS/MS assay. Toxicology. 2012;292:33-41.

24. Zimmers SM, Browne EP, O'Keefe PW, Anderton DL, Kramer L, Reckhow DA, et al. Determination of free Bisphenol A (BPA) concentrations in breast milk of U.S. women using a sensitive LC/MS/MS method. Chemosphere. 2014;104:237-43.

25. Zhou J, Zhao S, Zhang J. An indirect competitive enzyme-linked immunosorbent assay for bisphenol-A based on the synthesis of a poly-L-lysine-hapten conjugate as a coating antigen. Anal Methods. 2013;5:1570-6.

26. Du L, Zhang C, Wang L. Ultrasensitive time-resolved microplate fluorescence immunoassay for bisphenol A using a system composed on gold nanoparticles and a europium(III)-labeled streptavidin tracer. Microchim Acta. 2015;182:539-45.

27. Maiolini E, Ferri E, Pitasi AL, Montoya A, Di Giovanni M, Errani $\mathrm{E}$, et al. Bisphenol A determination in baby bottles by chemiluminescence enzyme-linked immunosorbent assay, lateral flow immunoassay and liquid chromatography tandem mass spectrometry. Analyst. 2014;139:318-24.

28. Huang P, Zhao S, Eremin S. A fluorescence polarization immunoassay method for detection of the bisphenol A residue in environmental water samples based on a monoclonal antibody and 4'(aminomethyl) fluorescein. Anal Methods. 2015;7:4246-51.

29. Kim A, Li CR, Jin CF, Lee KW, Lee SH, Shon KJ, et al. A sensitive and reliable quantification method for Bisphenol A based on modified competitive ELISA method. Chemosphere. 2007;68:1204-9.

30. Zhou W, Cao Y, Sui D, Lu C. Radical pair-driven luminescence of quantum dots for specific detection of peroxynitrite in living cells. Anal Chem. 2016;88:2659-65.

31. Wang Z, Teng X, Lu C. Orderly arranged fluorescence dyes as a highly efficient chemiluminescence resonance energy transfer probe for peroxynitrite. Anal Chem. 2015;87:3412-8.

32. Cao Y, Sui D, Zhou W, Lu C. Highly selective chemiluminescence detection of hydroxyl radical via increased $\pi$-electron densities of rhodamine B on montmorillonite matrix. Sensors Actuators B Chem. 2016;225:600-6.

33. Dong SC, Zhong JP, Lu C. Introducing confinement effects into ultraweak chemiluminescence for an improved sensitivity. Anal Chem. 2014;86:7947-53.

34. Ullman EF, Kirakossian H, Singh S, Wu ZP, Irvin BR, Pease JS, et al. Luminescent oxygen channeling immunoassay: measurement of particle binding kinetics by chemiluminescence. Proc Natl Acad Sci U S A. 1994;91:5426-30.

35. Ullman EF, Kirakossian H, Switchenko AC, Ishkanian J, Ericson $\mathrm{M}$, Wartchow CA, et al. Luminescent oxygen channeling assay 
$\left(\mathrm{LOCI}^{\mathrm{TM}}\right)$ : sensitive, broadly applicable homogeneous immunoassay method. Clin Chem. 1996;42:1518-26.

36. Cauchon E, Liu S, Percival MD, Rowland SE, Xu D, Binkert C, et al. Development of a homogeneous immunoassay for the detection of angiotensin I in plasma using AlphaLISA acceptor beads technology. Anal Biochem. 2009;388:134-9.

37. Poulsen F, Jensen KB. A luminescent oxygen channeling immunoassay for the determination of insulin in human plasma. J Biomol Screen. 2007;12:240-7.

38. Zhao L, Lin JM. Development of a micro-plate magnetic chemiluminescence enzyme immunoassay (MMCLEIA) for rapid-and high-throughput analysis of $17 \beta$-estradiol in water samples. J Biotech. 2005;118:177-86.

39. Wang S, Wei X, Du L, Zhuang H. Determination of bisphenol A using a flow injection inhibitory chemiluminescence method. Lumin J Biol Chem Lumin. 2005;20:46-50.
40. Lu C, Li J, Yang Y, Lin JM. Determination of bisphenol A based on chemiluminescence from gold(III)-peroxymonocarbonate. Talanta. 2010;82:1576-80.

41. Liu LR, Liu LQ, Chen XQ, Shi GQ. Development of a highly sensitive chemiluminescence enzyme immunoassay for the determination of bisphenol A. Adv Mater Res. 2013;726:1283-6.

42. Zhang J, Zhao SQ, Zhang K, Zhou JQ. Cd-doped ZnO quantum dots-based immunoassay for the quantitative determination of bisphenol A. Chemosphere. 2014;95:105-10.

43. Xu S, Deng M, Sui Y, Zhang Y, Chen F. Ultrasensitive determination of bisphenol A in water by inhibition of copper nanoclustersenhanced chemiluminescence from the luminol-KMnO4 system. RSC Adv. 2014;4:44644-9.

44. Weller MG, Weil L, Niessner R. Increased sensitivity of an enzyme immunoassay (ELISA) for the determination of triazine herbicides by variation of tracer incubation time. Microchim Acta. 1992;108: 29-40. 